\title{
Media Pembelajaran Pengenalan Komponen Hardware Komputer Menggunakan Augmented Reality berbasis Android
}

\author{
Renbarka Dwi Septana ${ }^{1}$, Mardi Yudhi Putra ${ }^{2}$, Ahmad Safei ${ }^{3}$ \\ ${ }^{1}$ Manajemen Informatika; Universitas Bina Insani; Jl. Raya Siliwangi No. 6, Rawa Panjang Kota \\ Bekasi, 02182436886 / 02182436 996; e-mail: renbarkadwi99@gmail.com \\ ${ }^{2,3}$ Rekayasa Perangkat Lunak; Universitas Bina Insani; Jl. Raya Siliwangi No. 6, Rawa Panjang \\ Kota Bekasi, 02182436886 / 02182436 996; e-mail: mardi@binainsani.ac.id ; e-mail: \\ syafei456@gmail.com \\ * Korespondensi:e-mail: mardi@binainsani.ac.id
}

Diterima: 09 Desember 2020; Review: 21 Desember 2020; Disetujui: 28 Desember 2020

Cara sitasi: Septana RD, Putra MY, Safei A. 2020. Media Pembelajaran Pengenalan Komponen Hardware Komputer Menggunakan Augmented Reality. Information Management for Educators and Professionals. Vol 5 (1): 65 - 74.

\begin{abstract}
Abstrak: Teknologi informasi memberikan dampak yang signifikan dalam mendukung perkembangan media pembelajaran. Salah satu teknologi yang membantu dalam proses pembelajaran adalah Augmented Reality. Augmented Reality merupakan teknologi yang menggabungkan benda maya $2 \mathrm{D}$ atau $3 \mathrm{D}$ secara realtime yang diproyeksikan terhadap dunia nyata melalui devices seperti smartphone. Permasalahan yang diamati pada proses belajar mengajar di SMK, yakni materi pembelajaran disajikan dalam buku Lembar Kerja Siswa bergambar dua dimensi (2D) berwarna hitam putih sehingga siswa kesulitan memahami dan mengenali komponen hardware. Selain itu, belum memanfaatkan teknologi Augmented Reality sebagai media pembelajaran yang interaktif. Tujuan penelitian ini adalah membuat media pembelajaran dengan teknologi Augmented Reality sebagai alat bantu pembelajaran agar siswa dapat memahami materi pengenalan komponen hardware komputer. Model pengembangan penelitian ini menggunakan Multimedia Development Life Cycle (MDLC). Tools yang membantu dalam pebuatan Objek gambar 3D menggunakan Adobe Illustrator, Sketchup, Vuforia, dan Unity. Untuk bahasa pemrograman C\# yang dibuat menggunakan software Microsoft Visual Studio. Hasil penelitian berupa aplikasi YATINDO AR sebagai media pembelajaran komponen hardware komputer dengan teknologi Augmented Reality berbasis android yang telah membantu para guru dalam memberikan pemahaman kepada siswa tentang materi yang ada pada buku Lembar Kerja Siswa (LKS).
\end{abstract}

Kata kunci: Android, Augmented Reality, Media Pembelajaran, Hardware

\begin{abstract}
Information technology has a significant impact in supporting the development of learning media. One of the technologies that helps in the learning process is Augmented Reality. Augmented Reality is a technology that combines $2 D$ or $3 D$ virtual objects in realtime that are projected to the real world via devices such as smartphones. The problems observed in the teaching and learning process at SMK, namely the learning material are presented in a black and white two-dimensional (2D) illustrated Student Worksheet book so that students have difficulty understanding and recognizing hardware components. In addition, they have not yet utilized Augmented Reality technology as an interactive learning medium. The purpose of this research is to create learning media with Augmented Reality technology as a learning aid so that students can understand the material on the introduction of computer hardware components. This research development model uses the Multimedia Development Life Cycle (MDLC). Tools that help in creating 3D image objects using Adobe Illustrator, Sketchup, Vuforia, and Unity. For the $C$ \# programming language created using Microsoft Visual Studio software.
\end{abstract}


The result of the research is the YATINDO AR application as a learning media for computer hardware components with Android-based Augmented Reality technology which has helped teachers in providing understanding to students about the material in the Student Worksheet (LKS) book.

\section{Keywords: Android, Augmented Reality, Learning Media, Hardware}

\section{Pendahuluan}

Media pembelajaran merupakan sarana penyalur pesan atau informasi belajar yang hendak disampaikan oleh sumber pesan kepada sasaran atau penerima pesan tersebut. Penggunaan media pengajaran dapat membantu pencapaian keberhasilan belajar [1]. Berbagai model pembelajaran diterapkan agar proses pembelajaran dapat dilakukan dengan mudah, salah satunya adalah pembelajaran berbasis android [2]. Perkembangan teknologi pada sekolah sudah mulai menggunakan kecanggihan alat sebagai media pembelajaran, salah satu contohnya menggunakan teknologi Augmented Reality $(A R)$ yang berbasis Android. Aplikasi pembelajaran dengan teknologi Augmented Reality dapat digunakan oleh siswa-siswa di sekolah untuk mengenal kecanggihan teknologi yang mulai berkembang di dunia pendidikan.

Augmented Reality (AR) adalah teknologi dengan konsep menggabungkan dimensi dunia nyata dengan dimensi dunia maya yang di tampilkan secara realtime. Hal ini dilakukan dengan cara menampilkan objek 3D pada marker yang sudah di tentukan, adalah sebuah pola khusus yang bersifat unik dan dapat dikenali oleh aplikasi [3]. Augmented Reality merupakan teknologi dari cabang computer vision yang bertujuan untuk menggabungkan citra sintetis ke dalam dunia nyata menggunakan bantuan webcam. Gambar yang ditangkap kemudian diolah dan ditampilkan ke layar monitor[4]. Model 3 dimensi biasa digunakan sebagai alat bantu pengajaran untuk membuat para peserta didik lebih memahami materi yang diberikan [5]. Alat bantu teknologi yang berkaitan dengan komputer sangat dibutuhkan dalam proses pembelajaran yang lebih baik dan mudah. Misalnya saja alat pembelajaran untuk sub-sub bidang hardware komputer [6].

Augmented Reality tidak seperti realitas maya yang sepenuhnya menggantikan apa yang ada di dunia nyata, namun hanya sekedar menambahkan atau melengkapi. Hal ini dilakukan dengan cara menambahkan objek tiga dimensi pada marker, yakni sebuah pola yang bersifat unik dan dapat dikenali oleh aplikasinya. Smartphone memungkinkan pengembangan aplikasi Augmented Reality dengan murah serta dapat diakses oleh banyak pengguna [7]. Teknologi ini dapat membantu mengembangkan metode pembelajaran didalam dunia pendidikan.

SMK Tinta Emas Indonesia digunakan sebagai objek penelitian. SMK ini berada di Kota Bekasi sudah berpengalaman didalam dunia pendidikan dan dunia Industri. Selain itu, ikut serta berperan secara aktif dalam memberikan metode yang berbeda dalam menyajikan pendidikan. Permasalahan yang diamati pada proses belajar mengajar adalah materi pembelajaran pengenalan komponen hardware komputer disajikan dalam buku Lembar Kerja Siswa bergambar dua dimensi (2D) berwarna hitam putih sehingga siswa kelas $\mathrm{X}$ TKJ kesulitan memahami dan mengenali komponen hardware. Selain itu, belum ada media pembelajaran di sekolah yang memanfaatkan teknologi Augmented Reality sebagai media pembelajarannya serta kekurangan alat praktek untuk siswa dalam mempelajari komponen hardware komputer.

Tujuan penelitian ini adalah memanfaatkan teknologi Augmented Reality sebagai alat bantu pembelajaran, sehingga siswa lebih memahami materi pengenalan komponen hardware komputer. Dengan adanya teknologi $A R$ akan sangat membantu guru dan juga siswa dalam proses belajar mengajar. Siswa dapat mempelajari apa saja komponen hardware komputer tanpa perlu melihat secara fisik sehingga proses pembelajaran menjadi interaktif.

Untuk model pengembangan yang digunakan dalam merancang aplikasi media pembelajaran dengan teknologi Augmented Reality yaitu Multimedia Development Life Cycle (MDLC). Model pengembangan memiliki tahapan concept, design, material collecting, assembly, testing and distribution. MDLC digunakan karena dianggap memiliki tahapan yang merancang susunan pembuatan aplikasi multimedia, sehingga dapat memberikan hasil akhir berupa media pembelajaran komponen hardware komputer, dan dapat menyajikan materi yang dibutuhkan.

Multimedia Development Life Cycle (MDLC) merupakan metodologi pengembangan multimedia yang terdiri dari enam tahap, yaitu konsep (concept), desain (design), pengumpulan materi (material collecting), pembuatan (assembly), pengujian (testing), dan distribusi 
(distribution). Keenam tahap ini tidak harus berurutan dalam prakteknya, tahap-tahap tersebut dapat saling bertukar posisi [8].

Sedangkan tools untuk membuat objek 3D dan pembuatan AR berbasis android menggunakan Unitiy dan Vuforia. Unity $3 \mathrm{D}$ adalah sebuah tools yang terintegrasi untuk membuat bentuk objek tiga dimensi pada video games atau untuk konteks interaktif lain seperti visualisasi arsitektur atau animasi 3D realtime [9]. Vuforia merupakan software untuk augmented reality yang dikembangkan oleh Qualcomm, yang menggunakan sumber yang konsisten mengenai computer vision yang fokus pada image recognition [10].

Vuforia adalah Augmented Reality Software Development Kit (SDK) untuk perangkat mobile yang memungkinkan pembuatan aplikasi AR. SDK Vuforia juga tersedia untuk digabungkan dengan unity yaitu bernama Vuforia AR Extension for Unity. Vuforia merupakan SDK yang disediakan oleh Qualcomm untuk membantu para developer membuat aplikasiaplikasi Augmented Reality (AR) di mobile phones (iOS, Android) [3].

Hasil dari penelitian ini berupa aplikasi berbasis Android yang memangfaatkan teknologi AR, sehingga aplikasi ini diharapkan dapat membantu para guru dalam menjelaskan materi, dan juga membantu siswa dalam memahami pembelajaran.

\section{Metode Penelitian}

Teknik pengumpulan data yang dilakukan pada penelitian ini adalah observasi, wawancara, serta studi pustaka. Observasi, dengan melakukan pengamatan secara lansung pada SMK Tinta Emas Indonesia mengenai proses pembelajaran di sekolah. Wawancara, dilakukan dengan cara tanya jawab kepada kepala sekolah, kepala bidang kurikulum, staff, dan juga beberapa guru Teknik Komputer dan Jaringan yang ada di SMK Tinta Emas Indonesia. Studi pustaka, dilakukan dengan cara mencari jurnal dan buku, serta melakukan pengumpulan data terkait metode pembelajaran yang ada pada sekolah.

Setelah mengumpulkan data yang dilakukan dengan beberapa Teknik, maka data tersebut akan diolah dan dianalisis agar mendapatkan hasil akhir yang lebih bermanfaat. Dalam melakukan pengolahan data tersebut menggunakan model pengembangan Multimedia Development Life Cycle (MDLC). Model Pengembangan multimedia menurut Luther yang sudah dimodifikasi Sutopo, pada pengembangan MDLC ini terdapat beberapa tahap, namun pada penelitian ini hanya mencakup enam tahapan.

Multimedia Development Life Cycle (MDLC) yang bersumber dari Luther dan sudah dimodifikasi oleh Sutopo. Metodologi pengembangan multimedia tersebut terdiri dari enam tahap. Keenam tahap ini tidak harus berurutan dalam prakteknya, tahap-tahap tersebut dapat saling bertukar posisi. Meskipun begitu, tahap konsep memang harus menjadi hal yang pertama kali dikerjakan [11].

Concept, pada tahap awal pengembang ini, media pembelajaran yang akan dibuat memiliki konsep dan tujuan untuk menyajikan materi pembelajaran dalam bentuk efek virtual menggunakan teknologi Augmented Reality untuk membantu menampilkan objek tiga dimensi (3D) sehingga pembelajaran menjadi lebih interaktif. Materi yang disampaikan yaitu komponen dan perangkat keras komputer untuk siswa kelas X TKJ pada SMK Tinta Emas Indonesia.

Design, tahapan ini merancang aplikasi media pembelajaran dengan membuat tampilan menu utama. Perancangan digambarkan menggunakan diagram UML (Unified Modelling Language), diagram yang digunakan yaitu use case diagram dan activity diagram, serta adanya storyboard dalam perancangan aplikasi ini.

Material Collecting, tahapan ini yaitu melakukan pengumpulan data seperti objek tiga dimensi (3D) menggunakan aplikasi pendukung seperti Sketchup, objek tiga dimensi yang dibutuhkan antara lain teks, gambar sebagai marker atau target objek, dan objek 3D.

Assembly, pada tahapan ini, membuat semua objek gambar tiga dimensi (3D) pada aplikasi berdasarkan konsep, desain, dan semua bahan yang dikumpulkan, didukung oleh aplikasi antara lain Adobe Illustrator, Sketchup, Vuforia, dan Unity. Adapun bahasa pemrograman pada sistem aplikasi menggunakan bahasa pemrograman C\# yang dibuat menggunakan software Microsoft Visual Studio.

Testing, Setelah tahap pembuatan maka akan dilakukan tahap pengujian, tahapan pengujian ini dilakukan dengan menjalankan aplikasi YATINDO AR yang telah dibuat, untuk mengetahui hasil apakah masih ada kesalahan atau tidak pada aplikasi tersebut. Distribution, Tahapan akhir ini yaitu dimana aplikasi akan disimpan dalam suatu media penyimpanan. Jika aplikasi sudah berhasil di uji coba, maka aplikasi akan disimpan di Google Drive, yang nantinya 
guru dan siswa SMK Tinta Emas Indonesia dapat langsung mengakses aplikasi YATINDO AR dan juga marker book, serta gambar 2D komponen hardware komputer yang berwarna sehingga dapat dijadikan marker pada laptop/komputer jika tidak dapat menggunakan marker book.

Selain itu, adapun langkah-langkah dalam penyelesaian penelitian ini yang dijadikan sebagai skema pemikiran atau dasar-dasar pemikiran yang dimulai dari mengidentifikasi permasalahan penelitian, analisis kebutuhan, model pengembangan yang mengadopsi model MDLC, dan hasil akhir. Langkah-langkah penelitian ditunjukkan pada gambar 1 berikut.

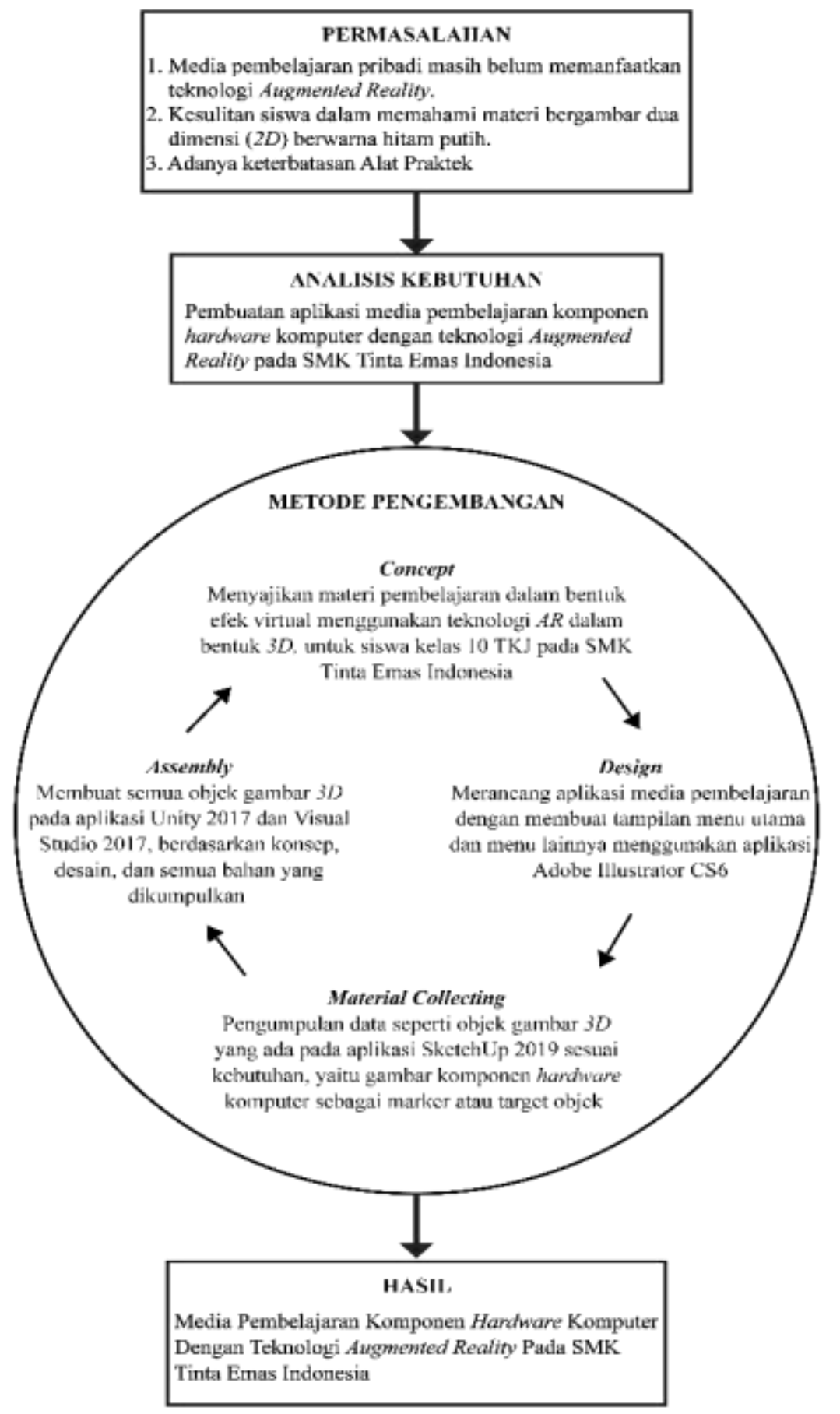

Sumber : Hasil Penelitian (2020)

Gambar 1. Langkah-langkah penelitian 
Permasalahan, pada tahap penelitian ini yaitu mencari pokok permasalahan yang ada pada sekolah SMK Tinta Emas Indonesia. Analisis Kebutuhan, menganalisis kebutuhan terkait masalah yang ada di sekolah dengan membuat aplikasi media pembelajaran menggunakan teknologi Augmented Realit. Bagian analisis kebutuhan terbagi menjadi analisis kebutuhan software dan aplikasi untuk menjalankannya. Metode Pengembangan, Tahapan ini merancang aplikasi menggunakan metode pengembangan MDLC. Hasil, Pada tahapan akhir ini akan memberikan hasil media pembelajaran komponen hardware komputer dengan teknologi Augmented Reality pada SMK Tinta Emas Indonesia.

\section{Hasil dan Pembahasan}

Hasil dan pembahasan pada penelitian ini meliputi analisis kebutuhan dalam membuat dan menjalankan aplikasi, perancangan perangkat lunak yang tunjukkan melalui usecase diagram, activity diagram dan implementasi program aplikasi untuk menu utama dan menu dalam memindai objek.

\section{Analisis Kebutuhan}

Bagian ini menjelaskan perangkat yang dibutuhkan dalam membuat dan menjalankan aplikasi media pembelajaran, adapun kebutuhan dalam membuat aplikasi yakni kebutuhan hardware dan software, selain itu juga diperlukan kebutuhan untuk menjalankan aplikasi.

Kebutuhan hardware sebagai alat pendukung untuk mengoprasikan perangkat lunak (software) dan membuat aplikasi. Pada tabel 1 kebutuhan hardware akan ditunjukkan kebutuhan minimal hardware yang digunakan:

Tabel 1. Kebutuhan Hardware

\begin{tabular}{ccc}
\hline No & Hardware & Spesifikasi \\
\hline 1 & Laptop & Processor Intel Core i5 7200 atau AMD Ryzen 5 \\
\hline 2 & Komputer & OS Win 8 mendukung 64bit \\
\hline & RAM 8 GB \\
\hline & VGA Intel HD 620 atau AMD Rx vega 8 \\
\hline & HDD 500 GB atau SSD 256 GB \\
\hline
\end{tabular}

Sumber: Hasil Penelitian (2020)

Selanjutnya, kebutuhan software yang dibutuhkan dalam pembuatan aplikasi yaitu Adobe Illustrator yang digunakan untuk membuat storyboard menu utama, Unity digunakan untuk membuat obyek 3D, Vuforia SDK digunakan developer untuk membuat Augmented Reality, Android SDK diperlukan untuk memulai mengembangkan aplikasi pada platform Android, SketchUp untuk mengumpulkan bahan gambar 3D, Visual Studio untuk membuat perintah pada sistem aplikasi. Kebutuhan software disajikan pada tabel 2 berikut.

Tabel 2. Kebutuhan Software

\begin{tabular}{cc}
\hline No & Software \\
\hline 1 & Adobe Illustrator CS6 \\
\hline 2 & Unity 3D 2017 \\
\hline 3 & Vuforia SDK \\
\hline 4 & Android SDK \\
\hline 5 & Google SketchUp 2019 \\
\hline 6 & Microsoft Visual Studio 2017 \\
\hline
\end{tabular}

Sumber: Hasil Penelitian (2020)

Kebutuhan untuk menjalankan aplikasi merupakan spesifikasi devices smartphone yang akan digunakan. Hal ini menjadi batasan minimal spesifikasi yang terdapat pada smartphone dalam menjalankan aplikasi media pembelajaran. Berikut kebutuhan untuk menjalankan aplikasi:

Tabel 3. Kebutuhan Menjalankan Aplikasi

\begin{tabular}{cc}
\hline No & Spesifikasi perangkat \\
\hline 1 & Smartphone OS Lollipop \\
\hline 2 & RAM 1 GB \\
\hline 3 & Kamera 5 MP \\
\hline 4 & Penyimpanan 150 MB \\
\hline
\end{tabular}

Sumber: Hasil Penelitian (2020) 


\section{Perancangan Perangkat Lunak}

Perancangan aplikasi media pembelajaran ini dibuat menggunakan Unifed Modelling Language (UML) untuk memudahkan dalam proses perancangan. Bagian perancangan ini yang menjelaskan beberapa tahapan yaitu usecase diagram yang menunjukkan interaksi antara aktor dengan sistem, skenario ditunjukkan dengan alur interaksi, activity diagram ditunjukan dengan aktifitas-aktifitas yang ada, dan storyboard. Berikut ini tahapannya yaitu:

1. Use Case Diagram

Tahapan ini merupakan ilustrasi tentang tata cara pengguna berinteraksi dengan sistem aplikasi untuk mengetahui fungsi dari sistem aplikasi tersebut. Aktor yang diidentifikasi pada bagian ini ada dua yakni siswa dan guru. Sedangkan case nya terdiri dari melihat cara penggunaan, membaca materi komponen hardware, melakukan pemindaian objek dalam hal ini gambar monitor yang dicetak pada selembaran kertas kemudian di pindai. Selanjutnya ada menu mengerjakan soal terkain komponen hardware, tentang adalah identitas pembuat aplikasi.

Pada gambar 2 ditunjukkan use case diagram Media Pembelajaran Komponen Hardware Komputer dengan Teknologi Augmented Reality pada Smk Tinta Emas Indonesia:

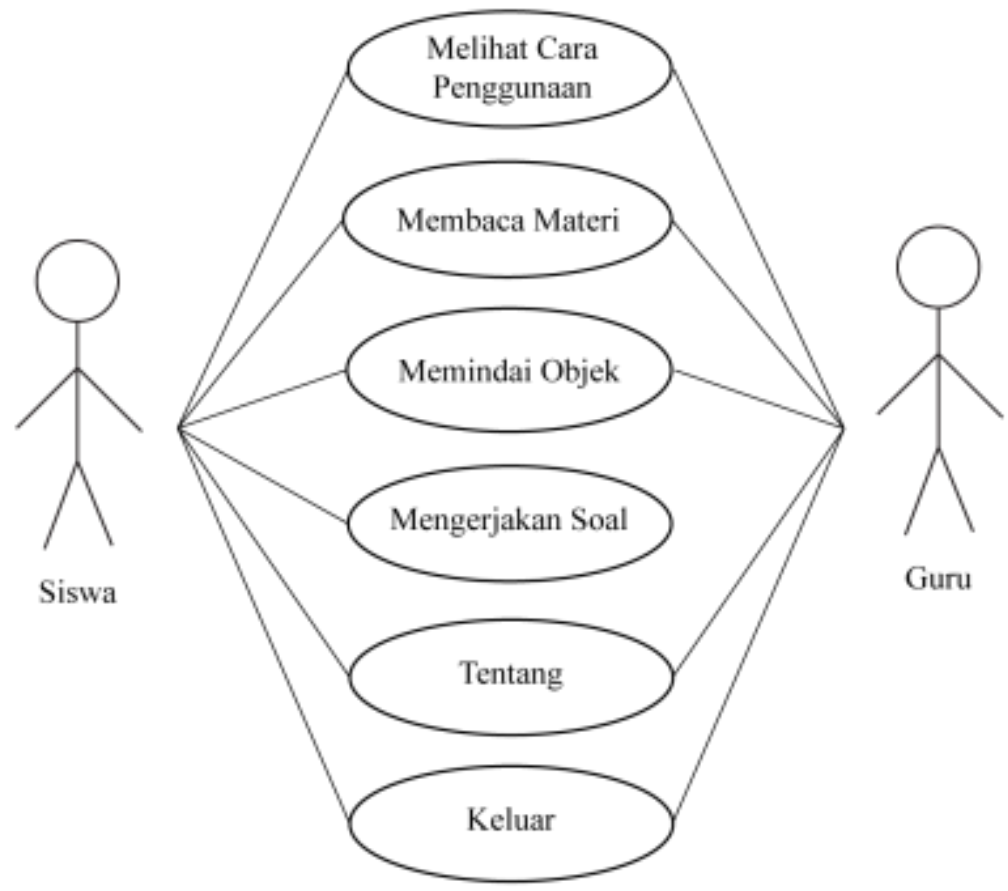

Sumber: Hasil Penelitian (2020)

Gambar 2. Use Case Diagram

\section{Skenario}

Pada bagian skenario, skenario merupakan ilustrasi dari interaksi yang dilakukan pengguna dalam hal ini siswa dan guru terhadap sistem aplikasi secara berurutan. Berikut pada tabel 4 ditunjukkan skenario menu pindai objek pada penggunaan aplikasi YATINDO AR.

Tabel 4. Skenario Menu Pindai Objek

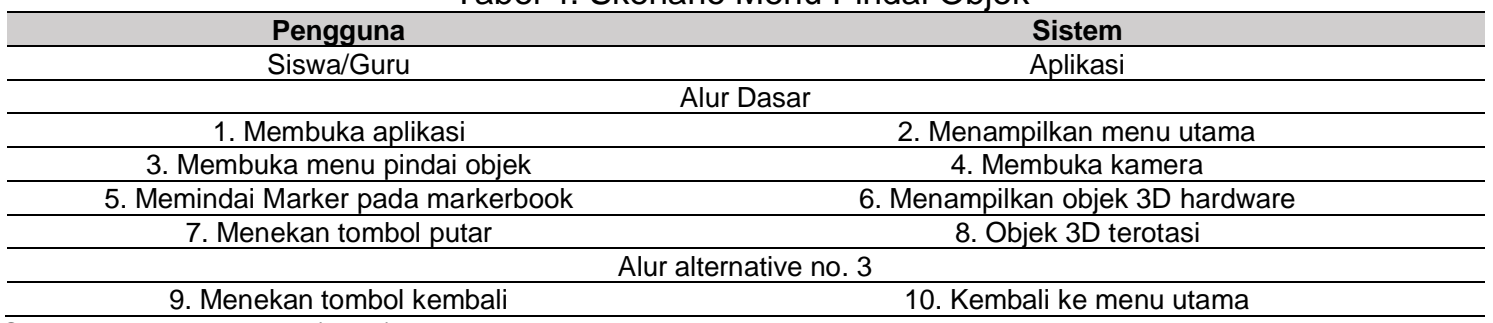

Sumber: Hasil Penelitian (2020) 
Pada tabel skenario menu pindai objek, siswa diharuskan memindai markerbook mengggunakan kamera smartphone, untuk melihat objek 3D komponen hardware komputer, sedangkan guru menjelaskan gambar objek 3D komponen hardware komputer.

\section{Activity Diagram}

Tahapan ini merupakan diagram yang menggambarkan tentang aktifitas dari pengguna dan sistem aplikasi. Dimulai dari pengguna membuka aplikasi, sistem menampilkan menu utama, pengguna memilih menu yang tersedia seperti menu memindai objek maka secara otomatis sistem akan membuka kamera Augmented Reality kemudian memindai markerbook.

Selanjutnya sistem akan menampilkan objek 3D yang sudah dipindai pada saat ini objek dapat dirotasikan oleh pengguna seperti rotasi ke kiri,kanan atas dan bawah. Berikut pada gambar 3 ditunjukan diagram aktifitas dari menu pindai objek.

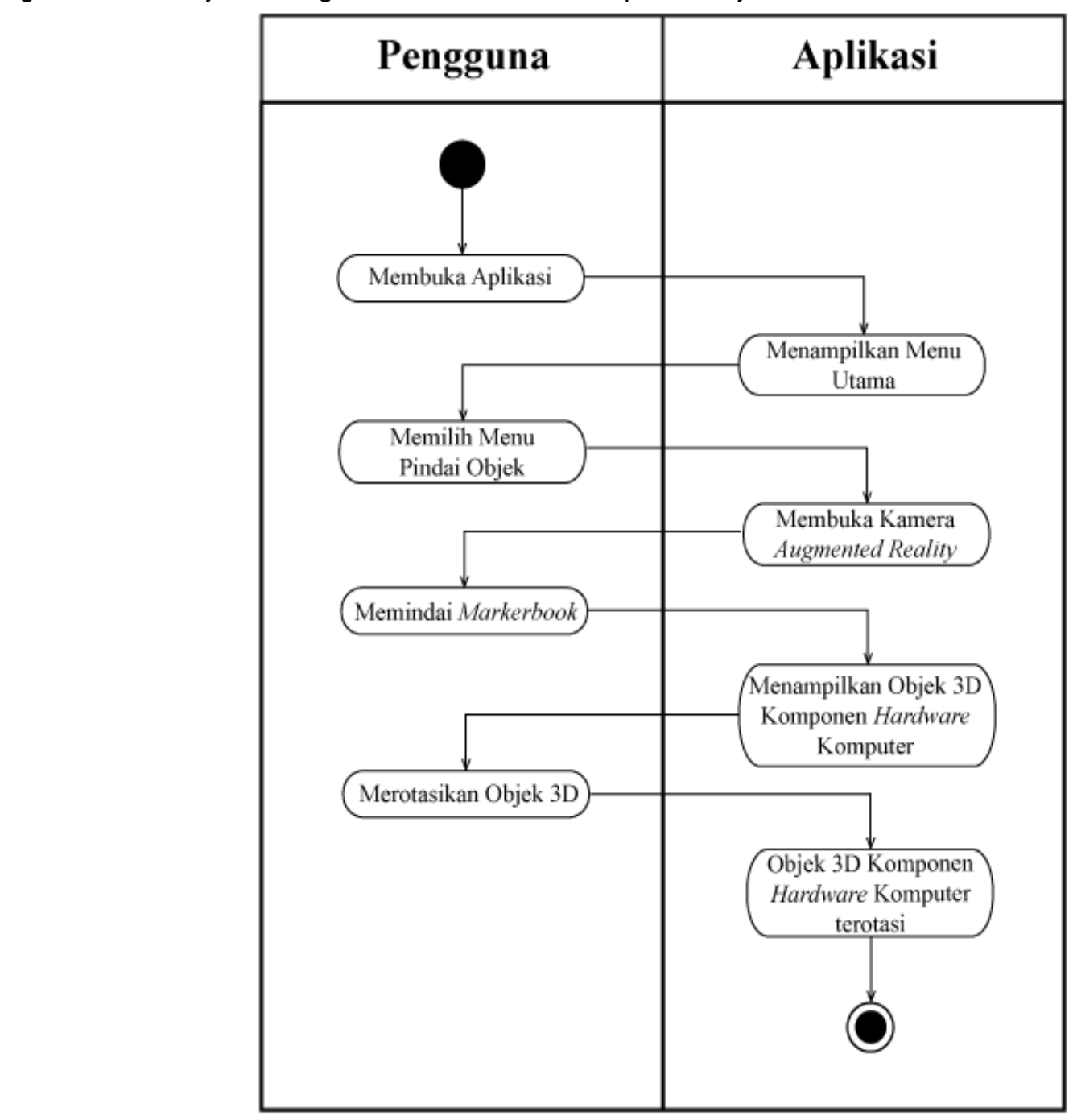

Sumber: Hasil Penelitian (2020)

Gambar 3. Activity Diagram Menu Pindai Objek

\section{Implementasi Perangkat Lunak}

Implementasi ini menjelaskan cara kerja sistem aplikasi dan hasil tampilan gambar berdasarkan yang telah dibuat pada tahap perancangan. Implementasi ini merupakan tampilan komponen hardware komputer yang dijadikan sebagai media pembelajaran pada SMK Tinta Emas Indonesia. Tampak terlihat menu pindai, materi dan soal pada aplikasi media pembelajaran.

Selain itu, terdapat logo sekolah di bagian kiri atas dan nama aplikasi di bagian kanan bawah menu utama yang ditunjukkan pada gambar 4 berikut. 


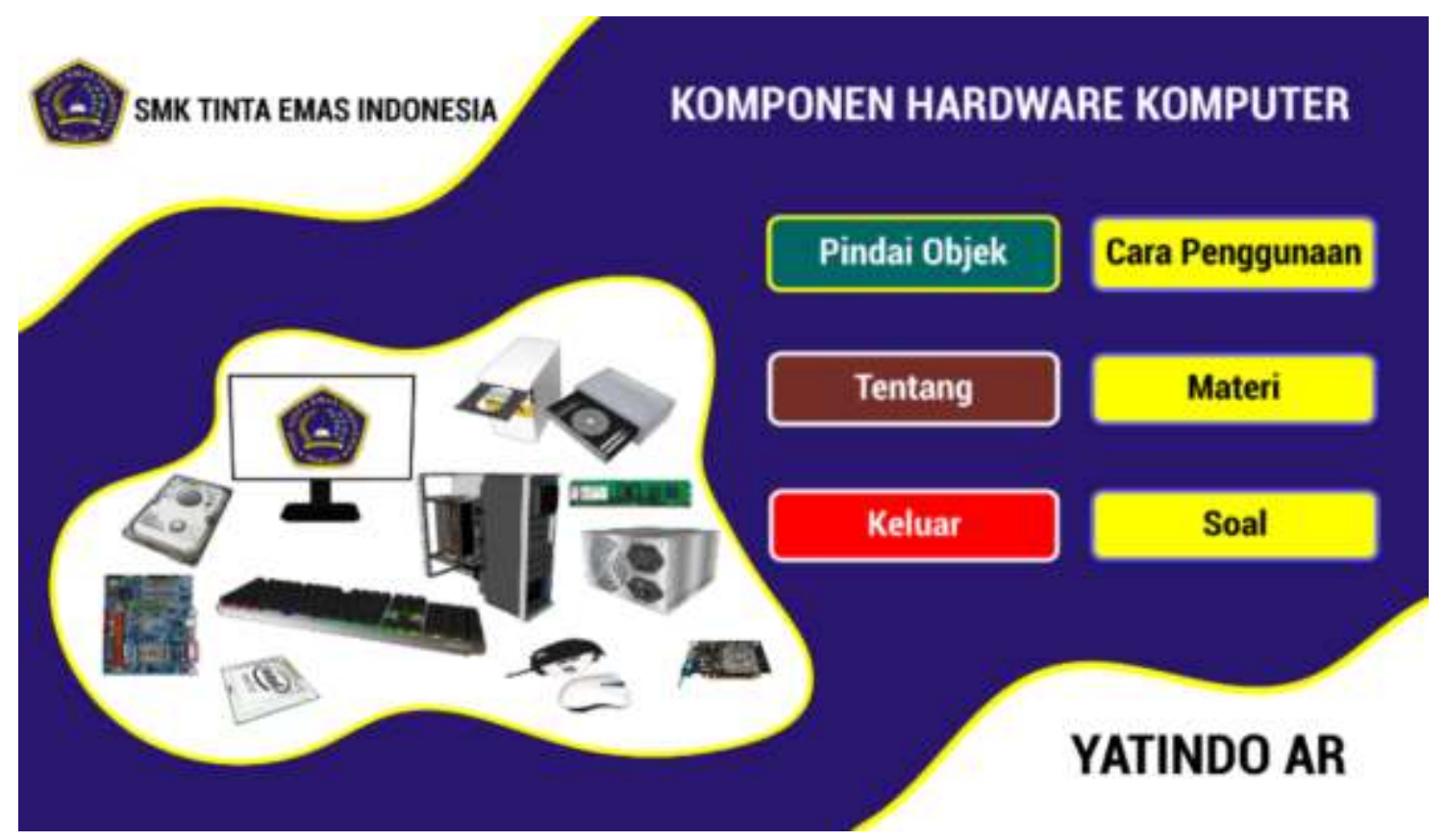

Sumber: Hasil Penelitian (2020)

Gambar 4. Implementasi Menu utama

Pada menu pindai objek, kamera AR akan terbuka, dan smartphone digunakan untuk memindai objek yang ada pada marker untuk memunculkan objek 3D dari komponen perangkat keras komputer. Setelah dipindai maka secara otomatis akan mucul objek 3D hasil pemindaian. Objek yang dipindai sesuai dengan marker yang telah dibuat sebelumnya. Dalam hal ini seperti monitor, mouse, keyboard dan personal komputer.

Berikut ini pada gambar 5 menunjukkan implementasi hasil dari pindai objek monitor perangkat lunak.

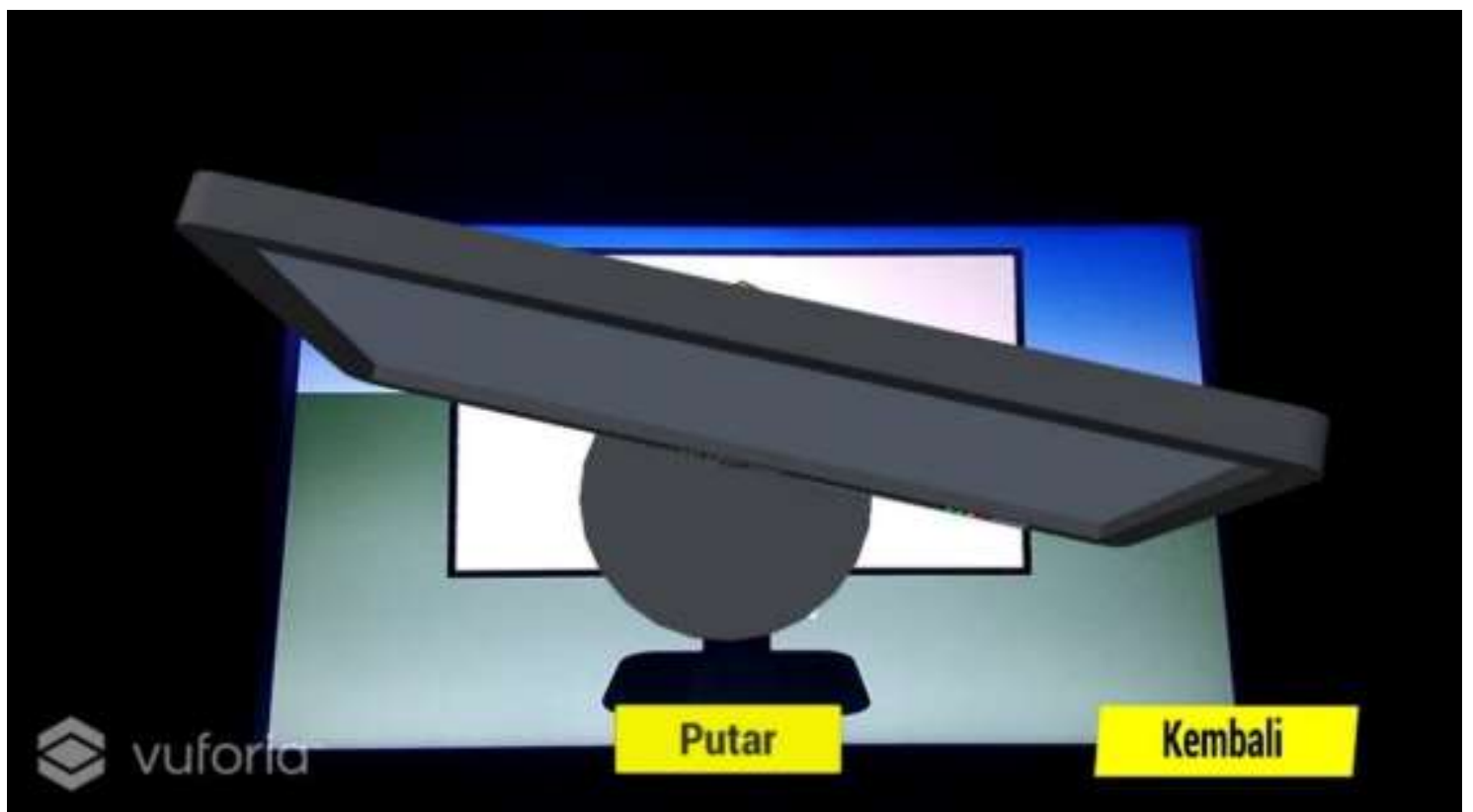

Sumber: Hasil Penelitian (2020)

Gambar 5. Implementasi Pindai Objek Monitor 


\section{Pengujian Aplikasi}

Tahapan ini merupakan pengujian aplikasi dengan metode Black Box Testing yang digunakan untuk mencari kesalahan sistem atau bug pada aplikasi pada saat digunakan. Disamping itu, pengujian ini dilakukan agar dapat diketahui secara fungsionalitas dari aplikasi media pembelajaran. Berikut ini merupakan hasil pengujian Black Box Testing pada aplikasi yang telah dibuat:

Tabel 5. Hasil Pengujian Aplikasi

\begin{tabular}{|c|c|c|c|c|}
\hline No & Fungsi yang di uji & Cara pengujian & Hasil yang diharapkan & Hasil pengujian \\
\hline 1 & Membuka aplikasi & $\begin{array}{l}\text { Klik shortcut aplikasi } \\
\text { pada smartphone }\end{array}$ & Menampikan menu utama & Valid \\
\hline 2 & $\begin{array}{c}\text { Membuka fungsi menu } \\
\text { cara penggunaan }\end{array}$ & $\begin{array}{c}\text { Menekan tombol Cara } \\
\text { Penggunaan }\end{array}$ & $\begin{array}{c}\text { Menampilkan menu cara } \\
\text { penggunaan }\end{array}$ & Valid \\
\hline 3 & $\begin{array}{c}\text { Membuka fungsi menu } \\
\text { materi }\end{array}$ & $\begin{array}{c}\text { Menekan tombol } \\
\text { Materi }\end{array}$ & Menampilkan isi materi & Valid \\
\hline 4 & Membuka menu soal & Menekan tombol soal & Menampilkan soal & Valid \\
\hline 5 & $\begin{array}{c}\text { Mengerjakan semua } \\
\text { soal }\end{array}$ & $\begin{array}{l}\text { Menekan tombol } \\
\text { pilihan ganda }\end{array}$ & Menampilkan nilai & Valid \\
\hline 6 & $\begin{array}{c}\text { Membuka fungsi menu } \\
\text { pindai objek }\end{array}$ & $\begin{array}{c}\text { Mengarahkan kamera } \\
\text { ke marker Book }\end{array}$ & $\begin{array}{c}\text { Menampilkan objek 3D } \\
\text { komponen hardware komputer }\end{array}$ & Valid \\
\hline 7 & $\begin{array}{l}\text { Membuka fungsi menu } \\
\text { tentang aplikasi }\end{array}$ & $\begin{array}{l}\text { Menekan tombol } \\
\text { tentang aplikasi }\end{array}$ & $\begin{array}{l}\text { Menampilkan tentang tujuan } \\
\text { pembuatan aplikasi }\end{array}$ & Valid \\
\hline 8 & $\begin{array}{c}\text { Membuka fungsi menu } \\
\text { tentang pembuat }\end{array}$ & $\begin{array}{l}\text { Menekan tombol } \\
\text { tentang pembuat }\end{array}$ & $\begin{array}{c}\text { Menampilkan profil tentang } \\
\text { pembuat aplikasi }\end{array}$ & Valid \\
\hline 9 & Keluar dari aplikasi & $\begin{array}{l}\text { Menekan tombol } \\
\text { keluar pada menu } \\
\text { utama }\end{array}$ & $\begin{array}{c}\text { Keluar dari aplikasi YATINDO } \\
\text { AR }\end{array}$ & Valid \\
\hline
\end{tabular}

Sumber : Hasil Penelitian (2020)

\section{Kesimpulan}

Berdasarkan hasil penelitian yang telah dilakukan, adapun kesimpulan yang bisa diambil, antara lain: 1) Aplikasi yang dibuat dapat membantu para siswa dalam memahami komponen hardware komputer; 2) Dengan adanya gambar tiga dimensi (3D) siswa lebih mudah memahami materi komponen hardware komputer; 3) Aplikasi dengan teknologi augmented reality dapat memudahkan siswa dalam kegiatan pembelajaran, sehingga para siswa yang tidak belajar di dalam lab komputer tetap dapat mempelajari komponen hardware komputer menggunakan aplikasi ini.

\section{Referensi}

[1] M. Ikhbal and H. A. Musril, "Perancangan Media Pembelajaran Fisika Berbasis Android," vol. 5, no. 1, pp. 15-24, 2020.

[2] S. Jubaedah and M. Y. Putra, "Media Pembelajaran IImu Tajwid Berbasis Android Pada Lembaga Tahfidz Bina Santri," J. Mhs. BINA Insa. [S.I.], v. 4, n. 1, p. 47-58, aug. 2019. ISSN 2528-6919, vol. Vol 4 No 1, no. Vol 4 No 1 (2019): Jurnal Mahasiswa Bina Insani (Agustus 2019), pp. 47-58, 2019.

[3] I. Bagus and M. Mahendra, "Implementasi Augmented Reality ( $\mathrm{Ar}$ ) Menggunakan Unity 3D Dan Vuporia Sdk," J. IIm. ILMU Komput. Univ. Udayana, vol. 9, no. 1, pp. 1-5, 2016.

[4] R. Yulianto, "Augmented Reality Menggunakan Library Nyartoolkit Dan Bahasa C \#," vol. 3. No. 2, pp. 75-80, 2013.

[5] L. Kamelia, "Semar," Noviembre 2018, vol. IX, no. 1, p. 1, 2019, [Online]. Available: https://www.gob.mx/semar/que-hacemos.

[6] N. E. Putri, S. Marwan, and T. Hariyono, "Aplikasi Berbasis Multimedia Untuk Pembelajaran Hardware Komputer," J. Edik Inform., vol. 1, no. Pembelajaran Hardware Komputer, pp. 70-81, 2015.

[7] Santosa, A. Muqtadir, and D. K. Basuki, "Aplikasi Pengenalan Hardware Perangkat Keras Berbasis Android dengan Teknologi Augmented Reality," SNasPPM, no. September, 2018.

[8] D. Defrianto, R. Kridalukmana, and I. P. Windasari, "Pengembangan Permainan Edukatif Ragam Budaya Nusantara Berbasis Android," J. Teknol. dan Sist. Komput., vol. 3, no. 3, 
p. 379 , 2015, doi: 10.14710/jtsiskom.3.3.2015.379-386.

[9] A. Wiharto and C. Budihartanti, "Aplikasi Mobile Augmented Reality Sebagai Media Pembelajaran Pengenalan Hardware Komputer Berbasis Android," J. PROSISKO, vol. 4, no. 2, pp. 17-24, 2017.

[10] L. A. primandari Ellinda Dwi Fransiska, Tubagus Mohammad Akhriza, "Implementasi Teknologi Augmented Reality sebagai Media Pembelajaran Informatif dan Interaktif untuk Pengenalan Hewan," Semin. Nas. Sist. Inf. 2017, no. September 2017, pp. 636645, 2017.

[11] Y. Ashari, R. Kridalukmana, and I. P. Windasari, "Pembuatan Aplikasi Permainan Pengenalan Provinsi di Indonesia Melalui Game 'Adventure Indonesia' Berbasis Android," J. Teknol. dan Sist. Komput., vol. 4, no. 2, p. 389, 2016, doi: 10.14710/jtsiskom.4.2.2016.389-397. 